\title{
A DISCUSSÃO SOBRE AVALIAÇÃO NAS REUNIÕES ANUAIS DA ANPED NO PERÍODO 2000 A 2010
}

\author{
Itamar Mendes da Silva*
}

Recebido: 14 nov. 2011

Aprovado: 21 nov. 2012

\begin{abstract}
*Doutor em Educação (Currículo) pela Pontifícia Universidade Católica de São Paulo. Professor Adjunto no Departamento de Teorias do Ensino e Práticas Educacionais do Centro de Educação, da Universidade Federal do Espírito Santo. Vitória, ES, Brasil. E-mail: imendess1@uol.com.br
\end{abstract}

Resumo: O presente trabalho objetiva refletir sobre e divulgar resultados de investigação que buscou identificar a presença da discussão da temática avaliação nos trabalhos e pôsteres disponibilizados no sítio da ANPEd no período de 2000 a 2010. Focou-se o espaço ocupado pela avaliação nos GTs em que se organizam as Reuniões Anuais. Os resultados do estudo qualitativo indicaram que a temática representa menos de $3 \%$ do total de trabalhos e que as origens principais destes são pesquisas. Os/as autores/as, em geral, têm apenas um trabalho sobre o tema divulgado nos Anais. Também foi possível identificar reduzido número de autores/as produzindo continuadamente sobre o tema e concentração da produção em instituições do sudeste.

Palavras-chave: Avaliação. Estudos em avaliação. ANPEd.

THE ANNUAL ANPED`S MEETINGS ASSESSMENT DISCUSSION FROM 2000 TO 2010

Abstract: This paper aims to reflect on and release the results of an investigation that tried to identify the presence of assessment as a topic of discussion presented on posters and works available on ANPEd's web page during the period from 2000 to 2010. It focused on the space taken by assessment in the WGs (working groups) that organize the annual meetings. The results of this qualitative study indicated that this topic represents less that $3 \%$ of the amount of works and that their main origin is research. Most of the authors have just one paper on this topic on the analyzed proceedings. It was also possible to identify a small number of authors continuously producing on this topic and a majority of productions from southeastern institutions.

Key words: Evaluation. Assessment studies. ANPEd.

A avaliação vem sendo considerada como ação estratégica por vários setores da vida nacional. Essa preocupação com a avaliação parece vincular-se a um movimento geral pela melhoria da qualidade de produtos e processos de produção com a utilização de menos insumos, diminuição de custos e maximização de lucros. São avaliações de riscos para investidores internos e externos; da observância de Direitos Humanos; de leis de proteção à Infância e à Juventude, de desempenho escolar de crianças e jovens, de programas e projetos sociais etc (COHEN; FRANCO, 2007).

São várias as iniciativas implementadas desde a década de 1990, que ajudaram a criar e difundir no Brasil uma "cultura de avaliação" (MENEGHEL; 
LAMAR, 2001) ancorada em exames nacionais e internacionais de larga escala que buscam medir a proficiência da população escolar em leitura e matemática. O foco está no domínio de competências construídas ao longo dos primeiros anos de escolaridade (VILLAS BOAS, 2007).

O modelo de avaliação implementado se fundamenta na lógica neoliberal tornando-a instrumento de regulamentação e controle do Estado sobre a educação por meio da legislação e da cobrança de sua observância quer no nível municipal, estadual ou federal. O Estado assume, então, para si a responsabilidade pela avaliação - Estado Avaliador - e publicização dos resultados difundindo a idéia de que assim se aperfeiçoa a democracia, pois oferece ao cidadão condições de escolha na prateleira onde se pode encontrar exposta a educação. Nesse sentido as principais características deste modelo de avaliação a fazem: "quantitativa, competitiva, produtivista, fragmentada, baseada em exames nacionais distanciados da realidade local e seguem as determinações de organismos multilaterais" (RIBEIRO, 2008, p. 1).

A fim de dar conseqüência às opções de regulação e controle com publicização dos resultados a avaliação se torna progressivamente obrigatória no sistema educacional brasileiro desde os anos 1990 com a introdução do SAEB - Sistema Nacional de Avaliação do Ensino Básico - e do Provão. A partir de 2004 o Ministério da Educação - MEC - torna a Auto-Avaliação Institucional - AAI - obrigatória às Instituições de Ensino Superior - IES - públicas e privadas pertencentes ao Sistema Federal com a criação e introdução do SINAES - Sistema Nacional de Avaliação da Educação Superior. Também redes estaduais e municipais têm criado processos locais e regionais de avaliação e incentivado suas Unidades Escolares a implementarem AAI.

Os dados de desempenho de estudantes e instituições divulgados pelo Ministério da Educação - MEC - e/ou por organismos a ele subordinados ou com os quais coopera alcançam extraordinária repercussão na sociedade. Mesmo havendo discussão no meio educacional acerca da (im)possibilidade destes sistemas contribuírem para a real melhoria da qualidade de ensino no país (BAUER; SILVA, 2005). Dados de exames certificativos como o ENEM - Exame Nacional do Ensino Médio - e os divulgados por associações de classe - Ordem dos Advogados do Brasil (OAB) e Conselho Federal de Medicina $(\mathrm{CFM})$ - também referentes à qualidade dos cursos de graduação em direito e medicina causam grande repercussão e até certa comoção.

As avaliações promovidas pela CAPES - Coordenação de Aperfeiçoamento de Pessoal de Nível Superior - se colocam nesse contexto e têm como principal interesse regular o sistema a fim de promover a ampliação do nível e da quanti- 
dade da produção de conhecimento realizada em território nacional e os critérios são, em grande parte, os utilizados internacionalmente e/ou assemelhados àqueles (FREITAS, 2005). À discussão colocada subjaz o tema da qualidade ou de sua ausência nas escolas brasileiras de todos os níveis.

A difusão midiática de uma "cultura de avaliação" baseada em exames tem produzido reconhecimento público de sua importância e lhe imputado importantes responsabilidades no âmbito da qualificação da educação. A idéia prevalecente é que se realizando exames de proficiência como o Prova Brasil e de certificação como o ENEM se está fazendo avaliação e tornando público seu resultado se estará melhorando a qualidade da educação. É claro que a publicização pretende a responsabilização de profissionais da educação sediados nas escolas e também nas redes de ensino sem levar em consideração as diferentes condições objetivas de cada escola e rede de ensino. É como se a educação brasileira não tivesse uma história de descaso e se o acesso e a permanência já fossem garantidos a décadas ou séculos e os descuidados profissionais do setor tivessem que ser cobrados pelo mau desempenho dos/as alunos/as.

Porém, apesar das incompreensões e equívocos sobre a questão, toda essa importância dada pela sociedade refletida na mídia e pelos organismos do Estado parece não encontrar equivalente respaldo nos estudos e pesquisas que envolvem o tema da avaliação, ao menos do ponto de vista quantitativo. Nas Reuniões Anuais da ANPEd foram encontrados poucos trabalhos relacionados ao tema: nos 11 anos cobertos pelo levantamento menos de 3\% do total dos textos disponibilizados no sítio da Associação na forma de trabalhos e pôsteres aprovados para os Grupos de Trabalho - GTs - entre o ano 2000 (23 $3^{\text {a }}$ reunião anual) e 2010 ( $33^{\text {a }}$ reunião anual) tratam da avaliação.

Uma das possibilidades explicativas desta pouca produção parece ser o fato de que a ANPEd - Associação Nacional de Pós-Graduação em Educação -, reconhecidamente o mais expressivo fórum de debates da área educacional ${ }^{1}$, que mantém 24 Grupos de Trabalhos, não dedica nenhum destes espaços a discutir a questão de forma prioritária.

Diante do exposto parece ficar claro que desenvolver estudos e pesquisas sobre o tema da avaliação se torna importante no cenário educacional brasileiro a fim de buscar elementos para entender o caminho percorrido e o atual estágio das produções nacionais no âmbito da ANPEd.

1 Criada em 1976 a sociedade civil sem fins lucrativos congrega hoje sócios institucionais, ou seja, Programas de Pós-Graduação em Educação e sócios individuais - os professores/as, pesquisadores/as e estudantes de pós-graduação. A Instituição é considerada como importante interlocutora das questões ligadas à educação e à pesquisa no Brasil por organismos governamentais e acadêmicos, pode-se dizer que não há discussão importante referente à educação que não passe por suas Reuniões Anuais. 
Assim, o presente trabalho ${ }^{2}$ tem como objetivo publicizar e discutir resultados de pesquisa que buscou identificar e refletir sobre o percurso e o atual estágio das produções nacionais em avaliação apresentadas no âmbito dos GTs ${ }^{3}$ da ANPEd entre 2000 e 2010. Trata-se de um estudo longitudinal baseado em documentos envolvendo os materiais disponíveis à consulta pública no sítio da Instituição com foco nos trabalhos relacionados à avaliação. A análise foi organizada tendo em foco os seguintes itens: quantidades anuais e totais de trabalhos, sua distribuição pelos GTs, autores, origem institucional, palavras-chaves, metodologia e referências utilizadas pelos/as autores/as. Aqui se pretende discutir sobre o espaço ocupado pela avaliação nas Reuniões Anuais e nos GTs com a indicação das temáticas mais presentes; preocupar-se-á também com as principais origens institucionais do debate.

\section{A AVALIAÇÃO NOS GRUPOS DE TRABALHO DA ANPED}

Apesar de pequena a produção encontrada é expressivamente oriunda de pesquisa, diferentemente do que havia sido constatado em outros estudos como os de Souza (1995, 1996), Candau e Oswald (1995) e Vianna (1992) que mapearam a área até o final dos anos 1980, conforme aponta Barreto et al (2001) em trabalho que, focando os mais importantes periódicos da área, constrói quadro de tipo "estado da arte" até 1998 e suas conclusões não mudam significativamente em relação aos trabalhos anteriores. Importante acrescentar artigo de autoria de Borges e Calderón (2011) divulgando resultados de pesquisa apresentados na dissertação de mestrado de Regilson Maciel Borges concluída em 2010 na Pontifícia Universidade Católica de Campinas e que se propôs construir estado do conhecimento da produção divulgada pela revista Ensaio: avaliação e políticas públicas em educação, da Fundação Cesgranrio, entre 1999 e 2008 (BORGES, 2011).

As análises dos trabalhos e pôsteres habilitados para as Reuniões Anuais, no período de 2000 a 2010 mostraram de forma expressiva que o tema avaliação

2 A pesquisa contou com a participação de Flavia Soave Frezza como bolsista PIBIC - CNPQ no âmbito do Grupo de Pesquisa Qualidade de Ensino da PUC-Campinas então liderado pelo autor.

3 GT 2 - História da Educação, GT 3 - Movimentos Sociais e Educação, GT 4 - Didática, GT 5 - Estado e Política Educacional, GT 6 - Educação Popular, GT 7 - Educação da Criança de 0 a 6 anos, GT 8 - Formação de Professores, GT 9 - Trabalho e Educação, GT 10 - Alfabetização, Leitura e Escrita, GT 11 - Política de Educação Superior, GT 12 - Currículo, GT 13 - Educação Fundamental, GT 14 - Sociologia da Educação, GT 15 -Educação Especial, GT 16 - Educação e Comunicação, GT 17 - Filosofia da Educação, GT 18 Educação de Pessoas Jovens e Adultas, GT 19 - Educação Matemática, GT 20 - Psicologia da Educação, GT 21 - Afro-Brasileiros e Educação, GT 22 - Educação Ambiental, $\underline{\text { GT } 23}$ - Gênero, Sexualidade e Educação, GT 24 - Arte e Educação.

4 A dissertação em questão compõe Plano de Pesquisa mais amplo coordenado pelo autor deste artigo. 
ainda não dispõe de uma maior atenção deste fórum. Os dados apresentados a seguir mostram a quantidade anual de trabalhos aprovados e é eloqüente na explicitação dos espaços reservados à avaliação nas pesquisas que utilizam as Reuniões Anuais para serem apresentadas à comunidade acadêmica.

\begin{tabular}{cccccc} 
Reunião/Ano & Trabalhos & Pôster & Total & Selecionados & Referentes \\
\hline $23 a-2000$ & 263 & 75 & 338 & 42 & 15 \\
\hline $24 a-2001$ & 262 & 85 & 347 & 20 & 12 \\
\hline $25 a-2002$ & 195 & 71 & 266 & 12 & 11 \\
\hline $26 a-2003$ & 271 & 65 & 336 & 14 & 14 \\
\hline $27 a-2004$ & 304 & 69 & 373 & 13 & 11 \\
\hline $28 a-2005$ & 446 & 114 & 560 & 07 & 04 \\
\hline $29 a-2006$ & 333 & 64 & 397 & 05 & 05 \\
\hline $30 a-2007$ & 379 & 79 & 458 & 14 & 11 \\
\hline $31 a-2008$ & 347 & 78 & 425 & 11 & 10 \\
\hline $32^{a}-2009$ & 308 & 58 & 366 & 14 & 09 \\
\hline $33^{a}-2010$ & 346 & 50 & 396 & 15 & 11 \\
\hline Total & $\mathbf{3 4 5 4}$ & $\mathbf{8 0 8}$ & $\mathbf{4 2 6 2}$ & $\mathbf{1 6 7}$ & $\mathbf{1 1 3}$
\end{tabular}

Observando a tabela nota-se a existência de 4262 trabalhos e pôsteres publicados nos Anais da Anped nesse período de 11 anos, sendo 3454 trabalhos e 808 pôsteres. Em acordo com o critério definido, 167 trabalhos e pôsteres foram selecionados, sendo que 113 destes se confirmaram como referentes ao tema da pesquisa - 91 trabalhos e 22 pôsteres. A identificação destes considerou se os títulos possuíam palavras referindo-se diretamente à avaliação ou utilizavam termos que pudessem indicar relação com o tema: análise, estudos comparativos, verificação, mapeamento, impacto, percurso e/ou nomes de programas de avaliação. Após a $29^{a}$ Reunião Anual se pode ater também a presença de palavras-chave e aos resumos para o primeiro levantamento e confirmação da temática da avaliação presente no texto. É a partir desta edição que se pode identificar a presença de uma temática central a conduzir os debates ${ }^{5}$. Lembre-se que nos primeiros anos cobertos pela pesquisa (2000 a 2005) não eram exigidos resumos e palavras-chave o que obrigou à leitura integral dos artigos deste período cujos títulos indicavam possibilidade de enfocar a temática.

5 Educação, Cultura e Conhecimento na Contemporaneidade: desafios e compromissos foi o tema da $29^{\mathrm{a}}$ realizada em 2006; Anped: 30 anos de pesquisa e compromisso social foi o tema da $30^{\text {a }}$ edição realizada em 2007; no ano seguinte a $31^{\mathrm{a}}$ teve abordou o tema: Constituição Brasileira, Direitos Humanos e Educação; em 2009 a 32a discutiu: Sociedade, Cultura e Educação: novas regulações; a edição de 2010 teve por tema A Educação no Brasil: o balanço de uma década. 
Selecionados os artigos que tratavam do tema foram organizados em tabelas, com as informações necessárias à pesquisa.

Dentre os textos selecionados foi necessário indicar o GT de procedência de cada um, pois não existe espaço onde a pauta principal seja a avaliação, o que proporciona, em muitas vezes, que esta seja um tema secundário ou terciário no artigo, inclusive por indicação de palavras-chave.

Considerando o interesse social centrado na avaliação dos resultados da aprendizagem e que o ato de avaliar traz consigo valores e significados que servem a determinadas ideologias, revestidas de interesses situados em meio a disputas de poder (DIAS SOBRINHO, 2003), é possível encontrar soluções explicativas à produção sobre a avaliação aparecer centrada nos GTs 4, 5, 11 e 13 que se dedicam a discutir Didática, Estado e Política Educacional, Política de Educação Superior e Educação Fundamental, respectivamente.

Se considerarmos que a avaliação assume nos últimos anos papel preponderante nas definições de políticas públicas (BELLONI; MAGALHÃES; SOUSA, 2007) será possível construir hipóteses sobre sua presença nos debates do GT 05 (Estado e Política Educacional). Também se aplica o raciocínio ao GT 11 (Educação Superior) que tem sido levado a analisar, discutir, criticar e contrapropor políticas de avaliação institucional e de larga escala a que o setor está obrigado desde a década de 1990.

Quanto aos GTs de Didática e Ensino Fundamental pode-se depreender o entendimento da avaliação como parte constitutiva do processo didático e o foco na aprendizagem por um lado e a discussão dos exames (avaliações) em larga escala que tem nos Ensinos Fundamental e médio seus principais objetos por outro lado.

Diante do exposto também parece razoável tecer conjecturas acerca dos motivos que levaram pesquisadores/as, boa parte destes/as vinculados/as a GTs da ANPEd, a criar em 2003 a ABAVE - Associação Nacional de Avaliação Educacional - e não um GT no âmbito da Instituição ou criar as duas coisas. Importante destacar que várias áreas que congregam pesquisadores/as em GTs também possuem associações específicas.

As reuniões em que se computou maior quantidade de trabalhos e pôsteres foram a $23^{\mathrm{a}}$ realizada no ano 2000 , a $24^{\mathrm{a}}$ em 2001 e a $26^{\mathrm{a}}$ em 2003 , respectivamente com 15, 12 e 14 trabalhos e pôsteres. Destacam-se os anos das reuniões de 2005 e 2006 onde se apresentaram as menores quantidades de trabalhos ligados ao tema, chegando a ser apenas 04 e 05 respectivamente e nenhum pôster. Talvez se possa afirmar que essa maior produção na virada do milênio seja reflexo da chegada ao debate na ANPEd de pesquisas feitas a partir dos 
impactos do SAEB e do PROVÃO no início e em meados da década de 1990, respectivamente.

Nos últimos anos cobertos pela pesquisa se tem a Reunião Anual de 2009 pautando especificamente a questão das regulações no âmbito da sociedade, cultura e educação, donde se poderia esperar uma maior discussão acerca do tema, pois a avaliação tem sido utilizada como ferramenta de retroalimentação do processo de regulação do Estado brasileiro. Mas mesmo nesta $32^{\mathrm{a}}$ Reunião Anual a situação não se altera e a produção dos quatro últimos anos fica em 11, 10, 9 e 11 trabalhos e pôsteres, o que faz constatar: no âmbito da ANPEd há uma pequena, mas constante parcela da comunidade científica trabalhando em pesquisas e estudos sobre avaliação. Porem, é notável que a produção é baixa, menos de 3\% do total.

Dado ao histórico de sua difusão na sociedade se poderia supor que a academia entende que o tema já esteja suficientemente esquadrinhado e esgotado, mas parece que a repercussão social da avaliação dada por recentes fatos ligados ao ENEM - Exame Nacional do Ensino Médio - 2010, ao exame da OAB Ordem dos Advogados do Brasil - 2010 e pela ação de grupos de estudantes que boicotam o ENADE e mesmo à divulgação dos números do PISA indicam não ser o caso, a avaliação continua na ordem do dia. Também se poderia supor que dada às exigências e critérios da avaliação promovida pela CAPES os principais trabalhos têm sido publicado no formato de artigos em periódicos, porém contabilizamos desde a década de 1990 apenas duas revistas especializadas em discutir especificamente o tema, sendo uma a Avaliação - Revista da Avaliação da Educação Superior -, dedicada à educação superior e outra, a Estudos em Avaliação Educacional, com publicação maior de artigos referentes à Educação Básica. A terceira revista que foca o tema e traz a palavra avaliação em seu título não o faz de forma exclusiva, pois discute também políticas públicas em geral e o tema avaliação sequer representa a maioria dos artigos publicados (BORGES; CALDERÓN, 2011). Os livros novos (não re-edições) publicados exclusivamente sobre avaliação educacional nos últimos cinco anos também não são expressivos.

\section{ORIGEM DAS PESQUISAS}

Estudos ${ }^{6}$ caracterizados como "estado da arte" comumente afirmam que a produção teórica brasileira sobre avaliação durante certo tempo consistiu em traduções de obras produzidas no exterior, principalmente nos Estados Uni-

6 Além de Saul 1988, também os já indicados neste artigo. 
dos e divulgação de idéias de autores estrangeiros como: Tyler, Stufflebeam, Scrivem, Parlet \& Hamilton, Stake, House, MacDonald, Eisner entre outros. Também autores como Bloom, Patton, Worthen, Sanders, Fitzpatrick, entre outros, influenciaram a produção nacional. Mais recentemente autores europeus como Sacristán, Hadji, Perrenoud, Afonso, Fernandes passam a habitar nosso cenário educacional.

A principal produção nacional esteve nestes anos a cargo de autores vinculados, principalmente, a instituições de pesquisa independentes como a Fundação Carlos Chagas e Fundação Cesgranrio. A primeira edita a Revista Estudos de Avaliação desde 1990 e a segunda a revista Ensaio: Avaliação e Políticas Públicas em Educação e mantém, a partir de 2007, um curso de mestrado profissionalizante na área de avaliação.

É claro que as universidades montaram seus grupos de pesquisas e contribuíram com a produção nacional, mas são os periódicos destas duas instituições que mais publicaram ao longo do período pesquisado. Às universidades estão ou estiveram vinculados pesquisadores como Ana Maria Saul, Mere Abramowicz, Isabel Capeletti, Sandra Zákia Souza, Clarilza Prado Sousa, Bernardete Gatti, Maria Laura Franco, Luiz Carlos de Freitas, Nilton César Balzan, Mara de Sordi, Menga Lüdke, José Dias Sobrinho, Dilvo Ristoff, Isaura Belloni, Benigna Villas Boas, Ângela de Freitas Dalben, entre outros.

No âmbito das universidades temos nas $\mathrm{PUCs}^{7}$ de São Paulo, Campinas e Rio, nas estaduais UNICAMP, USP, UERJ, nas federais UFMG, UFSC e UNB o maior desenvolvimento de pesquisas vinculadas ao tema. É necessário informar que há pesquisadores/as destas universidades que acumulam atividades nas fundações: Cesgranrio e Carlos Chagas. A UNICAMP sediou a publicação da Avaliação - Revista da Avaliação da Educação Superior - durante muito tempo, mas atualmente a revista encontra-se sediada numa universidade comunitária, a Universidade de Sorocaba - UNISO - para onde se transferiu seu editor.

Como se pode constatar a Região Sudeste detém o maior número de universidades e centros de pesquisas que focam o tema. Também no âmbito da ANPEd isso se verifica e a região possui a maior produção, com 64 trabalhos e destaque para os estados de São Paulo e Rio de Janeiro. É seguida pela Região Centro-Oeste com 17 trabalhos e depois a Região Sul com um total de 16 trabalhos. As regiões Norte e Nordeste aparecem com 04 trabalhos cada uma.

A Região Sudeste é, com base nos trabalhos analisados, a que tem maior número de instituições onde se desenvolvem pesquisas envolvendo a avaliação com 22, em seguida se tem a Região Sul com 11 instituições listadas. O número

7 Para evitar repetições o significado das siglas é apresentado no quadro "Origem dos Trabalhos e Pôsteres". 
maior de produções oriundos da Região Sudeste também pode ser atribuído à existência de centros de pesquisa de renome como as fundações Carlos Chagas e Cesgranrio. Foi aí também que a Avaliação Institucional no ensino superior público ganhou maior destaque desde a década de 1990 (DIAS SOBRINHO, 2003). Ou seja, o poder e a riqueza regional do sudeste parecem fazer concentrar maior número de instituições, pesquisadores/as e, consequentemente, ampliar a produção de conhecimento: um persistente círculo vicioso.

As instituições de origem dos trabalhos e pôsteres podem ser visualizadas no quadro a seguir na próxima página.

Outro aspecto possível à análise diz respeito a pesquisadores/as interessados/as no tema. Antes de mostrar esses dados, é importante salientar que cada trabalho teve apenas seu primeiro/a autor/a considerado/a. A análise da relação de autores/as e quantidade de trabalhos durante o período pesquisado indica uma relação de 82 pessoas pesquisando e escrevendo sobre avaliação.

Os/a autores/as que mais escreveram sobre o tema produziram 03 trabalhos: Maria Teresa Esteban, Anamérica Prado Marcondes, José Carlos Rothen, vinculados a UFF, PUC-SP e UNITRI, respectivamente. Destas instituições as duas primeiras têm conseguido manter certa constância e variação de pesquisadores produzindo, o que não parece ser o caso da UNITRI, que se destacou a partir da obra e do interesse de um único e produtivo pesquisador e enquanto este lá esteve. O Professor em questão atualmente se encontra na Universidade Federal de São Carlos e continua produzindo sobre o tema.

Os outros 05 autores que escreveram dois trabalhos sobre o tema que também merecem destaque são: Dirce Nei Teixeira de Freitas, (USP); Suzana dos Santos Gomes (UFMG); Chelsea Maria de Campos Martins (UNESP); Márcia Ambrósio Rodrigues Rezende (UFMG) e Stella Cecília Duarte Segemreich (UCP). Frente a esses dados se conclui que a maioria dos textos pertence a autores pouco experientes no tema apresentando resultados de suas pesquisas de Mestrado ou Doutorado.

Quanto aos/às autores/as das pesquisas se pode constatar que aquele grupo de pesquisadores mais reconhecidos por tratarem do tema da avaliação não aparecem citados na lista dos que nestes últimos 11 anos desenvolveram pesquisas colocadas à discussão na ANPEd. Pode-se supor que estejam publicando em outros lugares como periódicos e livros, mesmo que não em periódicos especializados a discutir o tema.

Por fim, parece importante destacar o fato que as instituições que aparecem com maior número de publicações são públicas em sua maioria: USP com 08 trabalhos, UERJ com 07 trabalhos e UFF com 06 trabalhos e em seguida se têm 


\begin{tabular}{|c|c|}
\hline \multicolumn{2}{|l|}{ Origem dos Trabalhos e Pôsteres } \\
\hline Instituição & Qntd \\
\hline \multicolumn{2}{|l|}{ Região Norte } \\
\hline ANAMA - Universidade da Amazônia & 1 \\
\hline UFPA - Universidade Federal do Pará & 3 \\
\hline \multicolumn{2}{|l|}{ Região Nordeste } \\
\hline UFBa - Universidade Federal da Bahia & 1 \\
\hline UFC - Universidade Federal do Ceará & 1 \\
\hline UFPE - Universidade Federal de Pernambuco & 1 \\
\hline UFS - Universidade Federal de Sergipe & 1 \\
\hline \multicolumn{2}{|l|}{ Região Centro-oeste } \\
\hline PUC- Minas & 2 \\
\hline UnB - Universidade de Brasília & 3 \\
\hline UCDB - Universidade Católica Dom Bosco & 1 \\
\hline UFGD - Universidade Federal da Grande Dourados & 4 \\
\hline UFG - Universidade Federal de Goiás & 2 \\
\hline UNEMAT - Universidade do Estado de Mato Grosso & 1 \\
\hline Unileste - MG & 1 \\
\hline UniTri - Centro Universitário do Triângulo & 3 \\
\hline \multicolumn{2}{|l|}{$\begin{array}{ll} & \text { Região Sudeste } \\
\end{array}$} \\
\hline UFMG - Universidade Federal de Minas Gerais & 6 \\
\hline Escola Politécnica de Saúde Joaquim Venâncio/FIOCRUZ & 1 \\
\hline CUML - Cento Universitário Moura Lacerda & 1 \\
\hline FCC - Fundação Carlos Chagas & 1 \\
\hline PUC-CAMPINAS & 5 \\
\hline $\mathrm{PUC}-\mathrm{RIO}$ & 2 \\
\hline PUC - SP & 4 \\
\hline UNIABEU - Universidade Associação Brasileira de Ensino Universitário & 1 \\
\hline UCP - Universidade Católica de Petrópolis & 1 \\
\hline UNESA - Universidade Estácio de Sá & 3 \\
\hline UNICAMP - Universidade Estadual de Campinas & 3 \\
\hline UNESP - Universidade Estadual Paulista & 4 \\
\hline UERJ - Universidade Estadual do RJ & 7 \\
\hline USP - Universidade de São Paulo & 8 \\
\hline UFSCAR - Universidade Federal de São Carlos & 1 \\
\hline UFES - Universidade Federal do Espírito Santo & 3 \\
\hline UFF - Universidade Federal Fluminense & 6 \\
\hline UFRJ - Universidade Federal do RJ & 2 \\
\hline Universidade Federal Rural do Rio de Janeiro & 1 \\
\hline UMESP - Universidade Metodista de São Paulo & 1 \\
\hline UNIMEP - Universidade Metodista de Piracicaba & 1 \\
\hline UNISANTOS & 1 \\
\hline \multicolumn{2}{|l|}{ Região Sul } \\
\hline ISEPE - Instituto Superior de Ensino, Pesquisa e Extensão. & 1 \\
\hline PUC- RS & 1 \\
\hline UNERJ - Centro Universitário de Jaraguá do Sul & 1 \\
\hline UEL - Universidade Estadual de Londrina & 3 \\
\hline UEM - Universidade Estadual de Maringá & 1 \\
\hline UEPG - Universidade Estadual de Ponta Grossa & 1 \\
\hline UFPR - Universidade Federal do Paraná & 1 \\
\hline UFRGS - Universidade Federal do Rio Grande do Sul & 1 \\
\hline UFSC - Universidade Federal de Santa Catarina & 3 \\
\hline UFSM - Universidade Federal de Santa Maria & 1 \\
\hline UNISINOS - Universidade Federal do Vale do Rio c & 2 \\
\hline
\end{tabular}


a PUC-Campinas e UFMG com 05 trabalhos cada uma. Tal constatação parece indicar principalmente o interesse destas em relação à avaliação institucional que vem sendo implantada em várias IES - Instituições de Ensino Superior - desde a proposta do PAIUB e, mais recentemente, a partir do SINAES. O caso da única instituição não pública, PUC-Campinas, supõe-se encontrar justificação na existência desde 1998 de grupo de pesquisa voltado ao tema que congregou pesquisadores em torno da liderança do Prof. Newton Balzan e se ocupou durante anos do tema da avaliação.

Verifica-se atualmente um clima de debate entre governo, instituições e sociedade em torno da avaliação, indicada inclusive pelo documento final da Conae, que passa a ser fundamental nas discussões do meio acadêmico, porém estas ainda não encontram representação para se materializarem em pesquisas propostas à análise e ao debate no âmbito da principal associação da educação nacional.

Mas e as pesquisas realizadas e apresentadas nas reuniões anuais da ANPEd indicam que objetivos? Talvez estes possam ajudar a entender o porquê da escassez de estudos enfocando o tema.

\section{TEMÁTICAS E PROPÓSITOS DAS PESQUISAS}

A identificação dos objetivos dos trabalhos foi obtida não apenas do anúncio feito pelo/a autor/a, mas do cruzamento destes com as palavras-chave indicadas no texto. Tal cruzamento se fez em virtude que as palavras-chave são consideradas representativas do conteúdo do trabalho, isto é, são termos ligados central e diretamente ao tema ou problemática discutida e podem ajudar a indicar intenções do/a autor/a.

É importante relembrar que os trabalhos dos primeiros anos estudados não tinham indicadas as palavras-chave, pois não era requisito. Esses foram submetidos à leitura e as receberam pelo critério de foco principal e correlato. Além disso, chama-se atenção para a ordem das palavras-chave e quantidade, pois revelam o que é considerado central e prioritário pelo/a autor/a como tema de estudo. Cada trabalho teve basicamente três palavras-chave, mas existem trabalhos com mais e com menos também, por isso seu o número total não é exatamente a quantidade de trabalhos dividida por três.

Nas produções analisadas chama atenção a significativa variação de palavras-chave que podem indicar as opções teóricas de autores/as, mas também a tentativa de produzir teoria cunhando termos que pretendem marcar a área. Tal situação parece por um lado esclarecer que a temática merece ainda investimen- 
tos em seu desenvolvimento e por outro lado expressar a profusão de denominações também encontrada na literatura: Quantitativa, Somativa, Qualitativa, Formativa, Formadora, Mediadora, Diagnóstica, Dialógica, Emancipatória etc.

Assim, pode-se encontrar 62 indicações em que o termo avaliação aparece associado a alguma outra designação e em 22 vezes aparece sozinho, o que dá um total de 84. Para os propósitos deste artigo destacam-se aquelas designações de avaliação que pareceram focar a avaliação em si, mesmo que adjetivada, tipificada e/ou aplicada a um objeto em específico: assistida, cognitiva, educacional, externa, em larga escala, formativa, institucional, interna, processual, de aprendizagem, da aprendizagem on-line, de ensino, de ensino-aprendizagem, de monitoramento, de política, de políticas públicas, do ensino superior, universitária, na sala de aula e na licenciatura.

De todas essas expressões duas se destacam: avaliação institucional com 19 referências e avaliação de aprendizagem com 17. Outras palavras também mencionadas são educação superior e PAIUB - Programa de Avaliação Institucional das Universidades Brasileiras - com 14 e 07 referências respectivamente. Assim, pode-se afirmar que as maiores preocupações das pesquisas são sobre a avaliação da aprendizagem e institucional, esta segunda voltada ao Ensino Superior, fato que pode ser justificado pela própria natureza da ANPEd e pelos lugares de origens dos/as pesquisadores/as que habitam seus fóruns. Pode-se concluir ainda, por hipótese, que o tema 'avaliação institucional' no ensino superior preocupou antes os/as pesquisadores/as, em virtude dos contornos da avaliação da pós-graduação empreendida pela Coordenação de Aperfeiçoamento de Pessoal de Nível Superior - CAPES - e posteriormente da avaliação das universidades como um todo dentro do SINAES.

Por fim, mas não menos importante, é necessário fazer referência a outras palavras que constituíram a pesquisa nesse tópico, mesmo por que são maioria e, segundo se pode supor, expressam também em diferentes vocábulos aplicações, modelos e sentidos da avaliação, como por exemplo: auto-reflexão dos alunos, cotas para negros, CAPES, dispositivos pedagógicos, construção do aluno, desempenho escolar, ensinagem, portfólios, processo dialógico, políticas públicas, progressão continuada, reforma educacional, saber docente, formação de professores, gênero na escola, jornal em sala de aula etc.

A utilização desta variação de termos pode levar a supor situação mais desfavorável ainda à reflexão em torno do tema, pois mesmo na pequena quantidade de trabalhos (113 em 4262) sobre avaliação, esta não aparece sempre como o objeto principal de estudo. Talvez o fato de avaliação integrar o processo educacional possa explicar a dispersão na hora dos/as pesquisadores/as definirem 
os focos principais de seus trabalhos. E, por conta disso acabe aparecendo em pesquisas que não é o tema principal e sim coadjuvante, inclusive levando a palavra avaliação a aparecer como secundária e/ou terciária na ordem das palavras-chave.

As principais menções utilizadas pelos/as autores/as dos trabalhos reafirmam dois aspectos: aprendizagem e institucional. Sendo que ao longo do período coberto pelo estudo o aspecto institucional passa a ter maior destaque e apresentado teórica e politicamente em duas vertentes, a externa e a interna.

Apesar de não se ter compromisso de aqui discutir os fundamentos teóricos encontrados nos trabalhos - se pretende fazer isto oportunamente - e de as referências não variarem muito parece importante chamar atenção para a linha teórica expressa numa tese que vem ganhando força e se repetindo em linhas gerais nas análises realizadas mais recentemente. Esta faz opção pela pesquisa qualitativa, assume a inclusão da avaliação no âmbito político e social e incorpora a negociação como conceito. Parece atender as manifestas ambições de democratização das instituições educacionais em todos os níveis e de melhoria dos processos educativos ocorridos no interior destas: é o tema da qualidade.

Neste sentido parece importante destacar a afirmação de Ribeiro (2001) que a avaliação institucional é ainda um instrumento de desenvolvimento humano, já que só se consegue considerar o desenvolvimento institucional através do desenvolvimento humano, há assim, “[...] o reconhecimento de que a avaliação tem interesse público, e não meramente privado. Além de questões técnicas, há também éticas e políticas." (DIAS SOBRINHO, 2003, p. 28).

A avaliação, deste modo, fundamenta-se em um amplo e complexo processo que não se confunde com exames certificativos e/ou de proficiência; se transforma em instrumento fundamental, mas não exclusivo, para que a educação possa contribuir com o desenvolvimento do/a aluno/a, do/a professor/a, da escola, enfim, com a melhoria da qualidade do ensino e com a formação dos/as alunos/as, os/as quais poderão contribuir para a construção de uma sociedade mais justa, humana e igualitária.

\section{CONSIDERAÇÕES FINAIS}

O presente trabalho apresenta os resultados como primeiro esforço de mapear e indicar perspectivas utilizadas para se olhar a avaliação nas Reuniões Anuais da ANPEd no período entre 2000 e 2010. Esta análise inicial precisa ser aprofundada quanto aos aspectos conceituais e metodológicos a fim de produzir um quadro do tipo "estado da arte" acerca da temática no âmbito da ANPEd. É 
importante ressaltar que várias são as reflexões suscitadas por esta investigação e que ainda há muito que se desvendar, dada à pertinência da temática e sua importância para o campo educacional.

É fundamental indicar que mesmo não sendo o local mais privilegiado para o debate sobre avaliação pelos/as autores/as mais conhecidos/as a enorme expressividade do maior encontro nacional na área de educação tem servido para veiculação e debate de conceitos como "avaliação emancipatória" forjados/ construídos por pesquisadores/as brasileiros/as e de novos instrumentos/meios de avaliação como portfólio e Internet.

Ao concluir é importante repisar o terreno indicando a participação da avaliação nas disputas em torno dos rumos da educação. A avaliação vem sendo considerada como ação estratégica por diferentes setores para promoção de melhoria da qualidade da educação. Como exemplo pode-se citar a aplicação de exames gerais, com base no conceito de avaliação como medida destinada à classificação/ranqueamento e à responsabilização unilateral de profissionais e instituições educacionais. Essas práticas têm preocupado pequeno, mas importante e influente, conjunto de pesquisadores e teóricos do campo da educação e levado a ações ainda não extensas ou impactantes e fora do âmbito da ANPEd. Frente a isso, talvez se possa incitar a Associação a iniciar a discussão dos principais temas indicados pela Conae em suas próximas Reuniões Anuais a partir do último destacado na Carta disponível em seu sítio (www.anped. org.br) e destinada aos membros do Conselho de Governança do movimento "Todos pela Educação", ou seja, "Aperfeiçoar as políticas de avaliação e regulação, abrangendo os setores público e privado e aperfeiçoando os sistemas de avaliação.”.

Por fim, espera-se que esta primeira aproximação com os dados possam suscitar outras reflexões e incitar a comunidade acadêmica a pautar o tema para o debate mais amiúde, pois como afirmou Paulo Freire, "a educação precisa da avaliação como o peixe precisa de água limpa" e os dados são impactantes.

\section{REFERÊNCIAS}

BAUER, A.; SILVA, V.G. Saeb e qualidade de ensino: algumas questões. Estudos em Avaliação Educacional, São Paulo, v. 16, n. 31, jan./jun. 2005.

BARRETO, E. S. S. et al. Avaliação na educação básica nos anos 90 segundo os periódicos acadêmicos. Cadernos de Pesquisa, São Paulo, n. 114, 2001. 
BELLONI, I.; MAGALHÃES, H.; SOUSA, L.C. Metodologia de avaliação em políticas públicas. 4. ed. São Paulo: Cortez, 2007. (Col. Questões da Nossa Época)

BORGES, R. M. Avaliação na educação básica, o estado do conhecimento na revista Ensaio: avaliação e políticas públicas em educação (1999-2008). Campinas: Puc-Campinas, 2011.

BORGES, R. M.; CALDERÓN, A. I. Avaliação educacional: o estado do conhecimento da revista Ensaio: Avaliação e Políticas Públicas em Educação (1993-2008). Ensaio: aval.pol.públ.Educ., Rio de Janeiro, v.19, n.70, p.4356, mar. 2011.

COHEN, E. ; FRANCO, R. Avaliação de projetos sociais. 7. ed. Petrópolis: Vozes, 2007.

DIAS SOBRINHO, J. Avaliação: políticas educacionais e reformas na educação superior. São Paulo: Cortez, 2003.

FREITAS, L.C. (Org). Avaliação de escolas e universidades. Campinas: Komedi, 2005.

MENEGHEL, S. M.; LAMAR, A. R. Avaliação como construção social: reflexões sobre as políticas de Avaliação da Educação no Brasil. Avaliação, Campinas; Sorocaba, v. 6, n. 4, p. 17-26, dez. 2001.

RIBEIRO, C.M. Avaliação institucional: uma questão de desenvolvimento humano. In: ENCONTRO GOIANO DE AVALIAÇÃO INSTITUCIONAL, 4., 2001, Goiânia. Anais... Goiânia: UFG, 2001.

RIBEIRO, M.E.S. Políticas de avaliação institucional da educação superior: o caso da UFPA. In: REUNIÃO ANUAL DA ASSOCIAÇÃO NACIONAL DE PÓS-GRADUAÇÃO E PESQUISA EM EDUCAÇÃO, 31, 2008, Caxambu, MG. ASSOCIAÇÃO NACIONAL DE PÓS-GRADUAÇÃO E PESQUISA EM EDUCAÇÃO (BRASIL). Rio de Janeiro: ANPED, 2008. Disponível em: $<$ http://www.anped.org.br/reunioes/31 ra/1trabalho/ trabalho11.htm>. Acesso em: 22 jan. 2009.

SAUL, A. M. Avaliação emancipatória: desafio à teoria e à prática de avaliação e reformulação de currículo. São Paulo: Cortez; Autores Associados, 1988. 
VILLAS BOAS, B. Avaliação no bloco inicial de alfabetização no Distrito Federal. Estudos em Avaliação Educacional, São Paulo, v. 18, n. 36, jan./ abr. 2007. 